\title{
PREPARATION, CHARACTERIZATION, AND FORMULATION OF SOLID LIPID NANOPARTICLES LOTION FROM MULBERRY ROOTS (MORUS ALBA L.)
}

\author{
MUHAMAD WILDAN NUGRAHA, RADITYA ISWANDANA, MAHDI JUFRI*
}

Laboratory of Pharmaceutics and Pharmaceutical Technology Development, Faculty of Pharmacy, Universitas Indonesia, Depok, West Java, Indonesia. Email: mahdi.jufri@farmasi.ui.ac.id

Received: 20 September 2019, Revised and Accepted: 28 January 2020

\section{ABSTRACT}

Objective: Tween 80 has been used as a solvent for the extraction of phenolic compounds because this surfactant has both hydrophilic and hydrophobic properties. Solid lipid nanoparticles (SLNs) have been developed to improve penetration through the skin layer. We investigated the efficacy of using the microwave-assisted micellar extraction (MAME) approach for extracting oxyresveratrol from Morus alba roots and also to develop an SLN lotion.

Methods: The M. alba roots were extracted with Tween 80 in a microwave for $18 \mathrm{~min}$, and the extract was used to develop SLN with different concentrations of glyceryl monostearate. The SLNs from M. alba root extracts were prepared by a high-speed homogenization technique (25,000 rpm for $15 \mathrm{~min}$ ). The SLNs produced were characterized as per particle size, polydispersity index (PDI), and zeta potential. The SLNs with the best characteristics were used to formulate a lotion using a high-pressure homogenizer.

Results: Extraction using MAME showed improved extraction efficiency. The oxyresveratrol concentration from the extract was $2.77 \%$. The SLN with $2.5 \%$ glyceryl monostearate showed the optimum result, with a particle size of $130.20 \mathrm{~nm}$, a PDI of 0.278 , and a zeta potential of $-21.8 \mathrm{mV}$. The SLN lotion exhibited a particle size of $285.9 \mathrm{~nm}$ and a PDI of 0.360 . The SLN lotion also had good penetration, with a flux of $4.70 \mu \mathrm{g} \mathrm{cm}^{-2} / \mathrm{h}$.

Conclusion: MAME is an efficient method for extracting oxyresveratrol from M. alba roots. The SLN with 2.5\% glyceryl monostearate exhibited the optimum characteristics, and the SLN lotion showed good characteristics, including skin penetration.

Keywords: Microwave-assisted micellar extraction, Mulberry (Morus alba) roots, Solid lipid nanoparticle.

(C) 2020 The Authors. Published by Innovare Academic Sciences Pvt Ltd. This is an open access article under the CC BY license (http://creativecommons. org/licenses/by/4. 0/) DOI: http://dx.doi.org/10.22159/ijap.2020.v12s1.FF041

\section{INTRODUCTION}

The stability of the dosage form is essential because it can provide evidence of the quality of drug products over time in response to various environmental factors such as temperature, humidity, and light. The stability test of the preparation may also determine the duration of use of a drug product and its recommended storage conditions [1]. The stability of a pharmaceutical preparation can be divided into two types: Physical stability and chemical stability. The physical stability of the product is related to the physical form of the preparation such as sedimentation, creaming, flocculation, coalescence, and phase separation [2]. Physical stability of the preparations can be enhanced by physical development, such as the use of solid lipid nanoparticles (SLNs) [3].

SLN is a type of nanoparticle of an active compound comprising a solid lipid dispersed in an aqueous medium in the presence of a surfactant as an emulsifier. SLN can carry active compounds that are hydrophilic or hydrophobic. Furthermore, SLN can improve the physical stability of the preparation due to their small size [4]. SLN can be applied in various types of preparations, one of which is a lotion. A lotion is a topical preparation in the form of an emulsion and is commonly used as a medicine or cosmetic preparation. An SLN lotion can also deliver active nature-identical compounds.

Natural chemicals and extracts can be used in medicine and cosmetics. The need for beauty treatments is growing with the recognition of problems in the field of beauty such as skin brightness. One of the natural resources that can be utilized as skin lightening products is the mulberry plant (Morus alba L.). Mulberry plants are generally used as feed for the silkworm (Bombyx mori) [5]. However, the root of mulberry is still rarely utilized for its value as a cosmetic. Mulberry root can be utilized to brighten the skin due to oxidation activity by the tyrosinase enzyme. Mulberry extracts contain bioactive components, such as oxyresveratrol [6-8].

Oxyresveratrol can be obtained by extracting the mulberry root. Mulberry root extraction can be done in several ways, one of which is microwave-assisted extraction (MAE). Extraction using a microwave is more advantageous than conventional extraction because of shorter extraction times, the need for less solvent, and the observation that desirable results tend to be more common. MAE has been developed using a solvent in the form of a surfactant solution, the so-called microwave-assisted micellar extraction (MAME) technique. The extraction of oxyresveratrol can be carried out using a microwave with a surfactant solution, as the surfactant solution can increase the yield of phenolic compounds obtained [9]. Therefore, mulberry root extraction using the MAME method should achieve a more efficient recovery of oxyresveratrol.

Based on these explanations, the extraction efficiency of oxyresveratrol from the mulberry root by the MAME method should be improved, enabling its formulation into topical preparations in the form of SLN lotion for the development of pharmaceutical and cosmetic preparations. The physical characteristics of the SLN lotion are selected to improve the physical stability of the preparation, with small particle size making the preparation more stable. A lotion consisting of a water phase and an oil phase results in SLN containing lipid become more compatible. In addition, a lotion is also comfortable to use on a daily basis.

\section{METHODS}

Materials

Mulberry root from Rumah Sutera, Bogor, Tween 80, stearic acid, methylparaben, propylparaben, cetyl alcohol, lanolin, triethanolamine, 
and distilled water (Brataco Chemical, Indonesia), glyceryl monostearate (Croda, Singapore), oxyresveratrol (Shanghai Yuanye Bio-Technology, China), and lecithin 90G (Lipoid, Germany) were used.

\section{Methods}

Extraction

Mulberry root extraction (M. alba L.) was carried out by the MAME method. A total of $10 \mathrm{~g}$ of mulberry root powder was placed in a microwavable flask and to which was added a solution of $7 \mathrm{mM}$ Tween 80 concentration with a solid:solvent ratio of 1:30. The suspension was mixed vigorously and placed into the microwave appliance. The mixture was extracted for $18 \mathrm{~min}$ at $450 \mathrm{~W}$ of power, after which the resultant extract was centrifuged at $4000 \mathrm{rpm}$ for $5 \mathrm{~min}$.

\section{Characterization of extract}

The mulberry root extract was examined by the organoleptic test and by determining oxyresveratrol levels. Oxyresveratrol determination was conducted using high-performance liquid chromatography (HPLC). Using a modified version of the method described previously [6]: C18 column $(150 \times 4.6 \mathrm{~mm})$ with a flow rate of $1 \mathrm{~mL} / \mathrm{min}$ at $40^{\circ} \mathrm{C}$ and using a ultraviolet detector at $327 \mathrm{~nm}$ wavelength; the mobile phase was $0.1 \%$ acetic acid in water-acetonitrile, using an isocratic elution system [6]. The sample was dissolved in $70 \%$ ethanol, and the sample volume was $20 \mu \mathrm{L}$. The calibration curve was made with six concentrations, namely, $3.125,6.2512 .5,25,50$, or $100 \mu \mathrm{g} / \mathrm{mL}$ oxyresveratrol.

\section{Formulation of SLN}

Mulberry root extract was formulated into SLN with the following formulation. SLN was created using a high-speed homogenization method, modified from a previous method [10]. The first stage of making the SLN mulberry root extract involved heating glyceryl monostearate at $85^{\circ} \mathrm{C}$. Furthermore, a mixture of Tween 80 solution, lecithin, distilled water, and mulberry root extract was heated at $85^{\circ} \mathrm{C}$. Then, this hot water phase was added to the lipid phase and homogenized with a highspeed homogenizer at $24,000 \mathrm{rpm}$ for $15 \mathrm{~min}$, after which the resulting suspension was sonicated for $15 \mathrm{~min}$.

\section{Characterization of SLN}

The resulting SLN was characterized by an organoleptic test, as well as defined particle size and particle size distribution, using dynamic light scattering (DLS) and zeta potential. The SLN sample containing mulberry root extract was diluted with distilled water to an appropriate concentration, then particle size and particle size distribution were measured with the Malvern Zetasizer Nano series tool. Subsequently, a test of the efficiency of adsorption, based on a modification of Mappamasing et al. [11], was carried out by centrifuging $1 \mathrm{~mL}$ of SLNmulberry root extract for $50 \mathrm{~min}$ at 13,000 rpm [11]. The supernatant was used to determine the level of oxyresveratrol using HPLC. To determine how much oxyresveratrol was not incorporated into the SLN system, using the standard curve. The equation can calculate the number of active ingredients trapped in SLN (i.e., Drug Entrapment):

$$
\mathrm{DE}(\%)=\left(\frac{\mathrm{C}_{\mathrm{t}}-\mathrm{C}_{\mathrm{f}}}{\mathrm{C}_{\mathrm{t}}}\right) \times 100
$$

Where $\mathrm{C}_{t}$ is the initial concentration of the extract used in making the suspension, and $\mathrm{C}_{\mathrm{f}}$ is the amount of oxyresveratrol not incorporated into the SLN system.

The SLN with the best characteristics was then formulated into the lotion with the following formulation.

\section{Formulation of lotion}

The lotion preparation was followed using a modification of a previously described method [12]. The first stage of using the SLN extract of the mulberry root in the preparation of the lotion involved creating the lotion base.
The oil phase was prepared by melting stearic acid, cetyl alcohol, triethanolamine, methylparaben and also propylparaben, glyceryl monostearate, and lanolin. The second stage, the water phase, was prepared by dissolving glycerin in distilled water that has been heated at the same temperature at $70^{\circ} \mathrm{C}$. The oil phase was added slowly to the liquid phase, and homogenization was carried out at $750 \mathrm{rpm}$ using a homogenizer, after which the SLN extract of mulberry root was added, and the speed increased to $3000 \mathrm{rpm}$ to achieve a homogeneous suspension. Finally, the lotion formed was placed into a high-pressure homogenizer at 450 bar pressure for eight cycles.

\section{Lotion evaluation}

The lotion was evaluated organoleptically. DLS determined the particle size, polydispersity index (PDI), and zeta potential. The samples of the lotion SLN mulberry root extract were diluted with distilled water, then particle size and particle size distribution were measured by the Malvern Zetasizer Nano series. Then, the physical stability of the lotion was tested for 6 weeks. Tests performed were organoleptic, $\mathrm{pH}$ measurements, viscosity and rheology, cycling tests, mechanical tests, and storage tests at $4 \pm 2^{\circ} \mathrm{C}, 30 \pm 2^{\circ} \mathrm{C}$, and $40 \pm 2^{\circ} \mathrm{C}$. Then, a penetration test was performed with $1 \mathrm{~mL}$ lotion, and $1 \mathrm{~cm}^{2}$ rat's skin membrane is the initial concentration of the extract used in the suspension. The SLN with the optimal characteristics was then formulated into the lotion.

\section{RESULTS}

The characteristics of the mulberry root extract were brownish-black in color and distinctively flavored. The yield from the extraction was $2.05 \%$. The mulberry root extract had a moisture content of $9.83 \%$. The phytochemical screening results showed that the extract contained alkaloids such as saponins, tannins, phenolics, flavonoids, triterpenoids, and glycosides. The oxyresveratrol concentration in the vicious root extract with a concentration of $1005 \mu \mathrm{g} / \mathrm{mL}$ was $2.77 \%$. Time retentions using the C18 HPLC column of the oxyresveratrol standard were $6.57 \mathrm{~min}$ and $6.47 \mathrm{~min}$ from the mulberry root extract (Fig. 1).

The organoleptic characterization of the SLN mulberry root extract showed a distinctive brown color with a distinct flavor. There was little color difference between the different formulations, although $t$ formulation $\mathrm{A}$ had a lighter brown color than did formulations B and $\mathrm{C}$, whereas formulation $\mathrm{C}$ had a darker color than formulations $\mathrm{A}$ and $\mathrm{B}$ (Table 1).

The results of particle measurements based on the intensity of the three formulations, A, B, and C, showed different results depending on the concentration of glyceryl monostearate in the formulation (Table 2, Fig. 2). Formulation A had a particle size of $92.9 \mathrm{~nm}$, formulation B had a particle size of $130.2 \mathrm{~nm}$, whereas formulation $C$ had a particle size of $194.7 \mathrm{~nm}$. In addition, the PDI values of each formulation also differed. Formulation A had a PDI value of 0.269 compared with the PDI value of 0.278 (formulation B) and 0.438 (formulation C).

The zeta potential values of formulations $\mathrm{A}, \mathrm{B}$, and $\mathrm{C}$ varied in response to glyceryl monostearate concentration. Formulation A had a zeta

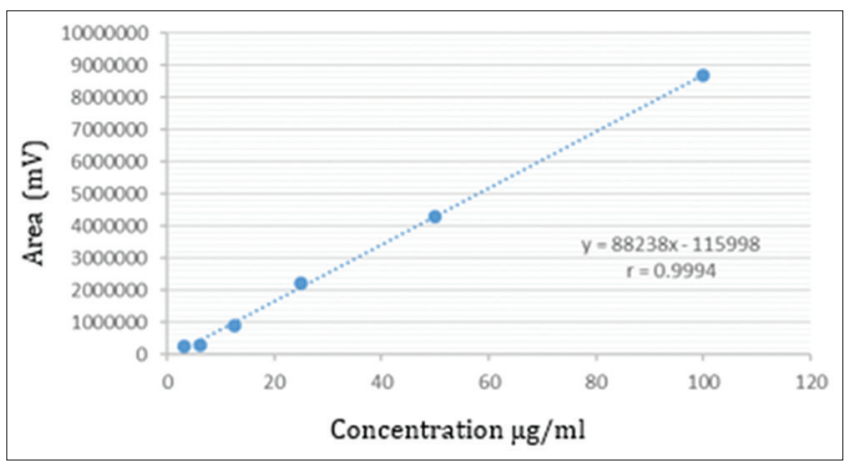

Fig. 1: Calibration curve of oxyresveratrol standard 
potential value of $-6.0 \mathrm{mV}$, compared with $-21.4 \mathrm{mV}$ (B) and $-29.8 \mathrm{mV}$ (C) (Table 3, Fig. 3).

The results from the measurement of the entrapment efficiency of each formulation showed an increase from formulation A to C. Formulation A had an entrapment efficiency value of $47.52 \%$, formulation B had an entrapment efficiency value of $78.27 \%$, whereas formulation $\mathrm{C}$ had an entrapment efficiency value of $81.67 \%$ (Table 4 ).

The results of the organoleptic evaluation of the SLN mulberry root extract lotion showed a physical appearance of a brownishwhite, distinctive-smelling, and fine-textured material. The particle measurement results based on the intensity of the SLN mulberry root extract lotion yielded a particle size of $285.9 \mathrm{~nm}$. In addition, the PDI value of the lotion was 0.360 , and the zeta potential value of the lotion was $-11.8 \mathrm{mV}$.

Table 1: Formulation of solid lipid nanoparticle mulberry root extract (Morus alba L.)

\begin{tabular}{|c|c|c|c|}
\hline \multirow[t]{2}{*}{ Materials } & \multicolumn{3}{|c|}{ Concentration $(\% \mathrm{w} / \mathrm{w})$} \\
\hline & Formulation $\mathrm{A}$ & Formulation B & Formulation C \\
\hline $\begin{array}{l}\text { Mulberry root } \\
\text { extract }\end{array}$ & 1 & 1 & 1 \\
\hline $\begin{array}{l}\text { Glyceryl } \\
\text { monostearate }\end{array}$ & 0.5 & 2.5 & 5 \\
\hline Lecithin 90G & 1 & 1 & 1 \\
\hline Tween 80 & 3 & 3 & 3 \\
\hline Distilled water & ad 100 & ad 100 & ad 100 \\
\hline
\end{tabular}

Table 2: Formulation of solid lipid nanoparticle mulberry root extract (Morus alba L.) lotion

\begin{tabular}{ll}
\hline Base of lotion & Concentration $(\% \mathbf{w} / \mathbf{v})$ \\
\hline SLN mulberry root extract & 40 \\
Cetyl alcohol & 1 \\
Stearic acid & 3.96 \\
Triethanolamine & 1.82 \\
Lanolin & 1.15 \\
Glyceryl monostearate & 0.38 \\
Glycerin & 1.15 \\
Methylparaben & 0.02 \\
Propylparaben & 0.08 \\
Distilled water & ad 100 \\
\hline
\end{tabular}

SLN: Solid lipid nanoparticles
The results of the cycling test showed a stable physical appearance of the SLN mulberry root extract lotion after six cycles, with no change in color, odor, phase separation, or crystal formation. In addition, the mechanical test results of the lotion showed no signs of instability, as no phase separation was found. After 6 weeks of storage, the preparation of the SLN mulberry root extract lotion at low temperature $\left(4 \pm 2^{\circ} \mathrm{C}\right)$, room temperature $\left(30 \pm 2^{\circ} \mathrm{C}\right)$, and high temperature $\left(40 \pm 2^{\circ} \mathrm{C}\right)$ showed stable physical appearance. No visible changes in color and odor were noted, and no phase separation was observed. The $\mathrm{pH}$ value of the SLN mulberry root extract lotion after 6 weeks showed no significant change. The rheological and viscosity measurements on the SLN mulberry root extract lotion showed plastic thixotropic flow properties. The test using spindle number 1 , at week 6 was lower, compared to week 0 at $30^{\circ} \mathrm{C}$ and $40 \pm 2^{\circ} \mathrm{C}$ storage temperatures.

The results of the penetration test showed better penetration from lotion SLN than lotion non-SLN. The flux value of the SLN mulberry root extract lotion was $4.70 \mu \mathrm{g} \mathrm{cm}^{-2} / \mathrm{h}$, which was higher non-SLN that had a flux value of $4.38 \mu \mathrm{g} \mathrm{cm}^{-2} / \mathrm{h}$ (Fig. 4).

\section{DISCUSSION}

The results of the oxyresveratrol concentration in the mulberry root, as extracted by the MAME method, had a higher than when compared with ethanol- or methanol-extracted extract using other extraction methods based on the previous studies. The concentration of oxyresveratrol following extraction with the ultrasonication method with methanol solvent was $0.27 \%[13]$.

The oxyresveratrol concentration in the mulberry root extract using the maceration method with ethanol $96 \%$ was $1.76 \%$ and also $0.85 \%$ if using $70 \%$ ethanol as solvent [6].

Microwaves can absorb electromagnetic energy and convert it to heat energy [14]. The resulting heat energy is delivered directly to the substance to be extracted so as to make the extraction process more efficient than conventional extraction methods [15]. The heat energy generated will heat the cell so that the pressure on the cell wall will increase. The increased pressure on the cell wall will cause the cell to expand and will push the cell wall from the inside so that the cell becomes ruptured. After the cell ruptures, the active compound will leave the cell [15].

Surfactants have hydrophobic and hydrophilic components and can absorb to the surface of the system at low concentrations by lowering surface tension through micelles [16]. Micelles are aggregates formed by a surfactant above the critical micelle concentration and comprise a



Fig. 2: Particle size of formulations A, B, and C 


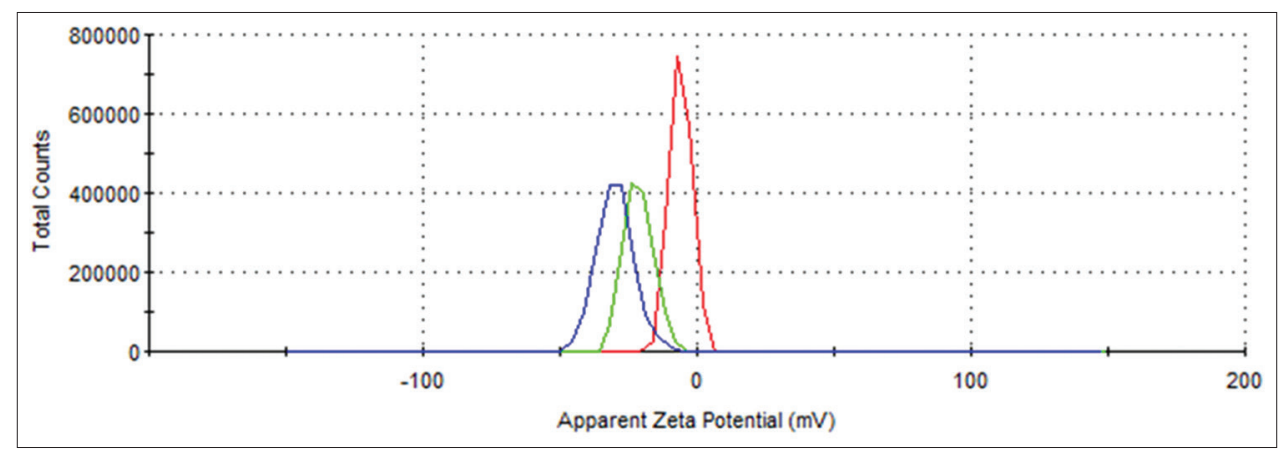

Fig. 3: Zeta potential of formulation A, B, and C

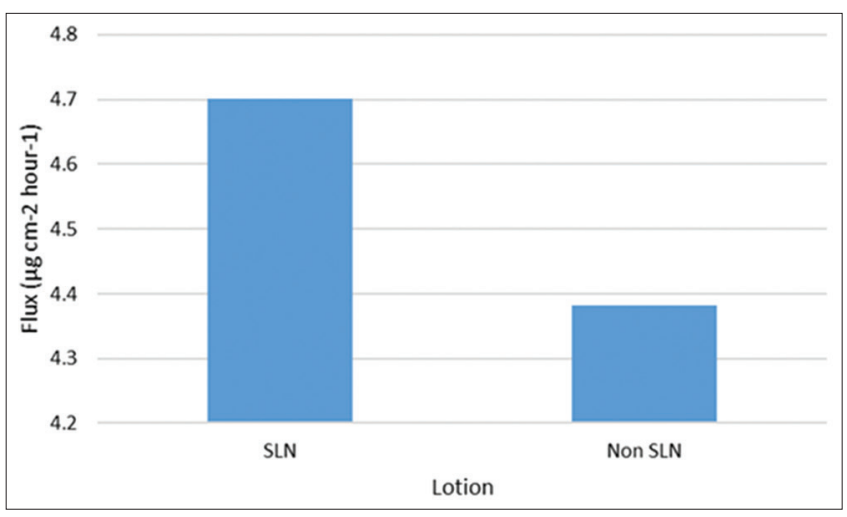

Fig. 4: Result of the penetration test

Table 3: Result of characterization solid lipid nanoparticle of mulberry root extract

\begin{tabular}{llll}
\hline Formulation & $\begin{array}{l}\text { Particle } \\
\text { size }(\mathbf{n m})\end{array}$ & $\begin{array}{l}\text { Polydispersity } \\
\text { index }\end{array}$ & Zeta potential $(\mathbf{m V})$ \\
\hline A & 92.91 & 0.269 & -6.0 \\
B & 130.2 & 0.278 & -21.4 \\
C & 194.7 & 0.438 & -29.8 \\
\hline
\end{tabular}

Table 4: Entrapment efficiency of formulations A, B, and C

\begin{tabular}{llll}
\hline Formulation & $\begin{array}{l}\text { Initial } \\
\text { concentration } \\
(\boldsymbol{\mu g} / \mathbf{m L})\end{array}$ & $\begin{array}{l}\text { Final } \\
\text { concentration } \\
(\boldsymbol{\mu g} / \mathbf{m L})\end{array}$ & $\begin{array}{l}\text { \% Entrapment } \\
\text { efficiency }\end{array}$ \\
\hline $\mathrm{A}$ & 195.55 & 102.62 & 47.52 \\
$\mathrm{~B}$ & 180.61 & 39.24 & 78.27 \\
$\mathrm{C}$ & 188.38 & 34.54 & 81.67 \\
\hline
\end{tabular}

hydrophilic surface and a hydrophobic nucleus that can interact with both hydrophilic and lipophilic substances [9]. The surfactant can improve the extraction and separation of oxyresveratrol from the plant so that the surfactant solution can increase the extraction efficiency, resulting in a higher yield of oxyresveratrol than occurs with other extraction solvents.

The difference in SLN color of the mulberry root extract was due to the difference in glyceryl monostearate concentration in the formulation. The lower the concentration of glyceryl monostearate, the brighter the SLN color. Besides, particle size and particle size distribution results showed a homogeneous dispersion because it had a PDI value of $<0.5$. The PDI ranges between 0 and 1 . A PDI value closer to 0 denotes a homogeneous dispersion, whereas an index $>0.5$ indicates a heterogeneous dispersion [17].

The zeta potential value of the SLN mulberry root extract also showed a result that was close to $-30 \mathrm{mV}$. The zeta potential exhibits electrostatic repulsive forces among the particles associated with the charge of the particle, thus preventing the aggregation of colloidal particles. A SLN or a colloid with a zeta potential of $-30 \mathrm{mV}$ tends to be stable during storage. The zeta potential values of formulations $B$ and $C$ were closer to $-30 \mathrm{mV}$ and tended to be more stable than formulation $\mathrm{A}$ [11]. The negative zeta potential value indicated that formulations $A, B$, and C had a negative charge. The negative charge of the three formulations can be attributed to the lecithin having a negative charge of the phosphate group [18]. The greater concentration of glyceryl monostearate used, result the more oxyresveratrol was extracted. Increasing the glyceryl monostearate concentration will provide more room for the active ingredient to be encapsulated in SLN $[11,19,20]$.

The particle size and particle size distribution results reflect the small particle size of the lotion, which help to make the lotion stable. Small particle sizes also allow the lotion to penetrate better into the skin. The PDI value of the lotion $(<0.5)$ also reflected a homogeneous dispersion.

The negative potential zeta value of the SLN mulberry root extract lotion was due to the SLN content of the mulberry root extract in the lotion and the presence of triethanolamine and stearic acid, which is anionic emulsifiers. In addition, SLN mulberry root extract also had a negative zeta potential value.

A cycling test in this study was conducted to examine the physical stability of the SLN extract of mulberry root lotion that has been tested against extreme temperature changes. Observations were made to understand clearly the changes that may occur.

The results of the cycling test showed a stable physical appearance of the lotion after six cycles with no change in color, odor, phase separation, or crystal formation. The composition of SLN and the surfactant in the formulation had been able to stabilize the emulsion system before and after the cycling test.

Mechanical testing aims to determine the effect of gravity effects on the stability of the preparation of SLN lotion preparation that had been formulated. According to Stokes' Law, the gravitational force obtained by the preparation during the storage process affects the stability and accelerates the separation of the emulsion system. Centrifugation at $3500 \mathrm{rpm}$ for $5 \mathrm{~h}$ is considered to be proportional to the gravitational force received by the preparation during storage for 1 year [21]. The results of the mechanical testing of the SLN lotion did not show any signs of instability as no phase separation was found. This can be interpreted that the SLN root extract lotion preparation exhibits a stable response to the effects of gravity for 1 year.

The physical stability test was performed on the mulberry root extract, which aims to determine the effect of several parameters on physical stability. Physical stability tests are also intended to ensure that the quality, safety, and effectiveness of pharmaceutical preparations during storage time are acceptable. The parameters observed in the test of physical stability during storage at various temperatures are organoleptic, $\mathrm{pH}$, rheology, and viscosity. The $\mathrm{pH}$ value is an important parameter to consider in the manufacture of pharmaceutical 
preparations. Pharmaceutical preparations may experience degradation, which accelerated or slowed exponentially in response to a decrease or increase in $\mathrm{pH}$. The $\mathrm{pH}$ value of lotion SLN of mulberry root extract for 6 weeks showed no significant change in $\mathrm{pH}$ value. This indicates that the SLN lotion extract of mulberry root was stable under all three storage conditions. Decreasing $\mathrm{pH}$ of SLN mulberry root extract lotion may be due to the oxidation events experienced by oxyresveratrol and other polyphenolic compounds. The oxidation process that causes the release of $\mathrm{H}+$ ions from the polyphenol compounds plays a role in decreasing the $\mathrm{pH}$ of the preparation [22].

Rheology is a complex study of fluid flow and deformation of solids in response to a given force. One of the things closely related to rheology is viscosity. Viscosity is defined as a measure of the resistance of a liquid to a given voltage. A substance is said to have a high viscosity value when its resistance size is large. In everyday terms, the viscosity is often defined as the viscosity of a liquid $[1,23,24]$. The result of the measurement of the lotion shows that it exhibits the properties of thixotropic plastic flow. The plastic flow properties are one of the nonNewtonian flow properties. The plastic flow curve does not go through the origin $(0,0)$ if the straight portion of the curve is extrapolated to the axis. However, the curve will bypass the axis of the shear stress at a certain point, known as the yield value. The existence of the yield value is due to contact between adjacent particles and must be decided before the flow can occur. Yield value indicates flocculation [1]. Flocculation in this lotion can be due to the size of the globules in it small and large surface area so as to increase the likelihood of flocculation, while the thixotropic flow is a decreasing curve that coincides with the ascending curve. A decreasing curve can occur if the shear rate is reduced when the maximum shear rate has been reached. The downward curve on the left of the ascending curve shows that the material has a lower consistency in shear velocity on the downward curve than in the ascending curve [1]. The viscosity value of this lotion is affected by the presence of cetyl alcohol, which can function as a thickening agent [25]. In addition, the use of high-pressure homogenizer also affects the viscosity of lotion as the greater the pressure and the more cycles are given, the lower the viscosity of lotion becomes. The decrease in viscosity of the lotion can be caused by the storage packaging, which is less tight, allowing the lotion absorbing water from the environment so that the volume of water in the formulation increases [23].

The SLN formula will increase the amount of drug on the skin because of the ability of the SLN to form an occlusive layer on the surface of the skin $[20,26]$. When SLN was applied on the surface of the skin, the water contained in the dosage would evaporate and leave the adhesive layer covering the skin, thus lowering the transepidermal water loss that facilitates the drug to penetrate the deepest layers of the skin. This occlusive effect was related to the SLN particle size. Nanoparticles sized will give an occlusive effect 15 times that of microparticles. The size of nanoparticles suitable for the formation of the occlusive layer on the skin must be below $400 \mathrm{~nm}[26,27]$. The nanoparticles in the SLN lotion obtained from this study had a size of $285.9 \mathrm{~nm}$.

\section{CONCLUSION}

Based on the above results, it can be concluded that the optimum formulation of SLN of mulberry root extract was obtained using $2.5 \%$ glyceryl monostearate. Lotion SLN had better penetration than did nonSLN lotion.

\section{CONFLICTS OF INTEREST}

The authors declare that there are no conflicts of interest.

\section{ACKNOWLEDGMENTS}

The authors acknowledge the financial support received from PTITA 2018 Universitas Indonesia, for their support and encouragement in carrying out his college work.

\section{REFERENCES}

1. Sinko PJ. Martin's Physical Pharmacy and Pharmaceutical Sciences. $5^{\text {th }}$ ed. USA: Lippincott Williams and Wilkins; 2006.

2. McClements DJ, Rao J. Food-grade nanoemulsions: Formulation, fabrication, properties, performance, biological fate, and potential toxicity. Crit Rev Food Sci Nutr 2011;51:285-330.

3. Raphael AP, Garrastazu G, Sonvico F, Prow TW. Formulation design for topical drug and nanoparticle treatment of skin disease. Ther Deliv 2015;6:197-216.

4. Ramadon D, Mun'im A. Utilization of nanotechnology in new drug delivery systems for natural material products. J Ilmu Kefarmasian Indones 2016;14:118-27.

5. Hutasoit R, Tarigan A, Ginting SP. Effect of Stem Cuttings Diameter on Seedling Growth in Four Species of Mulberry Plants (Morus sp.). Seminar Nasional Teknologi Peternakan dan Veteriner; 2013. p. 461-7.

6. Faizatun E, Anwar E, Djajadisasra J, Mardliyati E. The study of antioxidant and antityrosinase activity of extract from mulberry root (Morus alba L.). J Pharm Sci Res 2017;9:2004-8.

7. Kim YM, Yun J, Lee CK, Lee H, Min KR, Kim Y. Oxyresveratrol and hydroxystilbene compounds. Inhibitory effect on tyrosinase and mechanism of action. J Biol Chem 2002;277:16340-4.

8. Faizatun F, Asto SD. In vitro determination of sun protection factors on ethanol extract and nanostructured lipid carrier-based gel extract of mulberry root (Morus alba L.). Asian J Pharm Clin Res 2018;11:138-40.

9. Hosseinzadeh R, Khorsandi K, Hemmaty S. Study of the effect of surfactants on extraction and determination of polyphenolic compounds and antioxidant capacity of fruits extracts. PLoS One 2013;8:e57353.

10. Sangsen Y, Likhitwitayawuid K, Sritularak B, Wiwattanawongsa K, Wiwattanapatapee R. Novel solid lipid nanoparticles for oral delivery of oxyresveratrol: Effect of the formulation parameters on the physicochemical properties and in vitro release. Int J Med Sci Eng 2013;7:873-80.

11. Mappamasing F, Anwar E, Mun'im A. Formulation, characterization and penetration test of in vitro resveratrol solid lipid nanoparticles in topical cream. J Ilmu Kefarmasian Indones 2015;13:137-44.

12. Zulkarnain AK, Susanti M, Lathifa AN. The physical stability of lotion $\mathrm{O} / \mathrm{W}$ and $\mathrm{W} / \mathrm{O}$ from sphalerite macrocarpa fruit extract as sunscreen and primary irritation test on rabbit primer. Trad Med J 2013;18:141-50.

13. Ayinampudi SR, Wang Y, Avula B, Smillie TJ, Khan IA. Quantitative analysis of oxyresveratrol in different plant parts of Morus species and related genera by HPTLC and HPLC. J Planar Chromatogr 2011;24:125-9.

14. Destandau E, Thomas M, Claire E. Microwave-Assisted Extraction. In: Natural Product Extraction: Principles and Applications. Ch. 4. France: Royal Society of Chemistry; 2013.

15. Chemat FG. Microwave-Assisted Extraction for Bioactive Compounds: Theory and Practice. New York: Springer; 2013.

16. Rosen MJ. Surfactants and Interfacial Phenomena. $3^{\text {rd }}$ ed. Hoboken, NJ, USA: John Wiley and Sons, Inc.; 2004.

17. Avadi MR, Sadeghi AM, Mohammadpour N, Abedin S, Atyabi F, Dinarvand $\mathrm{R}$, et al. Preparation and characterization of insulin nanoparticles using chitosan and Arabic gum with ionic gelation method. Nanomedicine 2010;6:58-63.

18. Bueschelger HG. Emulsifier in Food Technology. New Delhi, India: Blackwell Publishing Ltd.; 2004.

19. Shah KA, Date AA, Joshi MD, Patravale VB. Solid lipid nanoparticles (SLN) of tretinoin: Potential in topical delivery. Int $\mathrm{J}$ Pharm 2007:345:163-71.

20. Lv Q, Yu A, Xi Y, Li H, Song Z, Cui J, et al. Development and evaluation of penciclovir-loaded solid lipid nanoparticles for topical delivery. Int J Pharm 2009;372:191-8.

21. Lachman L, Lieberman HA, Kanig JL. Theory and Practice of Industrial Pharmacy 1. (Siti Suyatmi, Translator). Jakarta: UI-Press; 1994. p. 1081.

22. El-Ishaq A, Obirinakem S. Effect of temperature and storage on Vitamin C content in fruits juice. Int J Chem Biomol Sci 2015;1:17-21.

23. Martin A, Swarbrick J, Cammarata A. Physical Pharmacy. $3^{\text {rd }}$ ed. Jilid II. (Joshita Djajadisastra, Translator). Jakarta: UI-Press; 1993. p. 93943, 1077, 1084-5, 1095.

24. Mitsui T. New Cosmetic Science. Amsterdam: Elsevier Science BV; 1998.

25. Rowe R, Sheskey P, Quinn M. Handbook of Pharmaceutical Excipients. $6^{\text {th }}$ ed. London: Pharmaceutical Press; 2009.

26. Wissing S, Lippacher A, Müller R. Investigations on the occlusive properties of solid lipid nanoparticles (SLN). J Cosmet Sci 2001;52:313-24.

27. Fadhila M, Mun'im A, Jufri M. A preparation, characterization, and in vitro skin penetration of Morus alba root extract nanoemulsion. Asian J Pharm Clin Res 2019;12:292-6. 